\title{
LETTERS
}

\section{Treatment of subclinical hypothyroidism in pregnant women}

Treatment using thyroxine (LT4) in women who are pregnant and have slightly elevated thyroid-stimulating hormone (TSH) remains controversial. Deshauer and Wyne ${ }^{1}$ provide brief, informative advice to help guide treatment. In their point four, they state that women with a TSH of more than $2.5 \mathrm{mIU} / \mathrm{L}$ and who are positive for thyroid perioxidase antibodies (TPOAb) should be treated to target the TSH level to the lower half of the trimester specific range. However, the advice from their source is misquoted and may lead to women being unnecessarily treated with thyroxine. The American Thyroid Association guideline for the diagnosis and treatment of thyroid disease during pregnancy and postpartum ${ }^{2}$ actually states, "LT4 therapy may be considered for TPOAbpositive women with TSH concentrations $>2.5 \mathrm{mU} / \mathrm{L}$ and below the upper limit of the pregnancy-specific reference range." (weak recommendation).
Language matters, because "should be treated" is not the same as "may be considered" - in the latter, the American Thyroid Association recognizes the lack of strong evidence for benefit for this group. More evidence does exist for treatment of overt hypothyroidism in women who are positive for TPOAb.

\section{Jacques S. Romney MD MSc}

Clinical professor, Division of Endocrinology and Metabolism, Department of Medicine, Faculty of Medicine and Dentistry, University of Alberta, Edmonton, Alta.

Cite as: CMAJ 2018 April 30;190:E545. doi: $10.1503 / \mathrm{cmaj} .733564$

\section{References}

1. Deshauer S, Wyne A. Subclinical hypothyroidism in pregnancy. CMAJ 2017;189:E941.

2. Alexander EK, Pearce EN, Brent GA, et al. 2017 Guidelines of the American Thyroid Association for the diagnosis and management of thyroid disease during pregnancy and the postpartum. Thyroid 2017;27:315-89.

Competing interests: None declared. 